\title{
In-Situ Analysis of Coarsening during Directional Solidification Experiments in High-Solute Aluminum Alloys
}

\author{
D. RUVALCABA, R.H. MATHIESEN, D.G. ESKIN, L. ARNBERG, \\ and L. KATGERMAN
}

\begin{abstract}
Coarsening within the mushy zone during continuous directional solidification experiments was studied on an Al-30 wt pet $\mathrm{Cu}$ alloy. High brilliance synchrotron X-radiation microscopy allowed images to be taken in-situ during solidification. Transient conditions were present during directional solidification. Under these conditions, solute-rich settling liquid flow affects the dendritic array and thus coarsening. Coarsening was studied by following the secondary dendrite arm spacing (SDAS) of a developing dendrite at different local solidification times according to the mush depth and instant interface velocity. Solute enrichment and liquid flow cause deceleration and acceleration of the solidification front, which in turn influences both the mush depth and local growth and coarsening due to variations in solutal gradients and thus local undercooling. In addition, spacing between neighboring dendrites (i.e., primary dendrite arm spacing), which determines permeability within the mushy zone, affects the development of high-order branches.
\end{abstract}

DOI: $10.1007 / \mathrm{s} 11663-008-9166-2$

(C) The Authors(s) 2008. This article is published with open access at Springerlink.com

\section{INTRODUCTION}

THE final solidified microstructure of alloys depends on the development of solid-phase morphology and segregation. During continuous solidification, growth and coarsening (i.e., dissolution of crystals or dendrite branches and growth of others) develop simultaneously. The final properties of an alloy are determined, in part, by the morphological evolution of the solid phase, which most often solidifies dendritically. The evolution of such ramified structure also influences microsegregation, which again affects the final properties of the solidified alloy. ${ }^{[1-3]}$

Coarsening of high-order branches is driven by compositional and geometrical gradients. These gradients cause material transport, i.e., solvent transport in the liquid from highly curved regions to regions with low curvature and vice versa for the solute element in the alloy. Different coarsening mechanisms have been described: (1) radial dissolution of weak dendrites arms and thickening of large ones; ${ }^{[4]}(2)$ dissolution of the root of weak arms (i.e., fragmentation):; ${ }^{[4-6]}$ (3) dissolution of weak dendrites from the tip toward the root; ${ }^{[7]}$ and (4) coalescence between neighboring dendrite arms. ${ }^{[8]}$

D. RUVALCABA, PhD Researcher, and D.G. ESKIN, Senior Scientist, are with the Materials Innovation Institute, 2628CD Delft, The Netherlands. Contact e-mail: d.ruvalcaba@m2i.nl R.H. MATHIESEN, Assistant Professor, and L. ARNBERG, Professor, are with the Norwegian University of Science and Technology, N-7491 Trondheim, Norway. L. KATGERMAN, Professor, is with the Delft University of Technology, 2628CD Delft, The Netherlands.

This article is based on a presentation given at the International Symposium on Liquid Metal Processing and Casting (LMPC 2007),

which occurred in September 2007 in Nancy, France.

Article published online August 14, 2008.
For dendritic solidification, coarsening can be described in terms of secondary dendrite arm spacing (SDAS). During coarsening, the spacing between secondary dendrite arms and high-order branches would tend to become larger in relation to the coarsening mechanisms mentioned previously. "SDAS characterization" has been well accepted in the metallurgical and material science community, and it is a term usually related to the mechanical properties of the alloy. A finer microstructure, i.e., low SDASs, usually improves the mechanical properties (e.g., yield strength). Both the cooling rate and composition show profound influence over the SDAS. For example, a finer microstructure is achieved by increasing the cooling rate..$^{[1,2]}$

A well-established relationship between SDAS and local solidification time $t_{s}$ is given by SDAS $\sim \mathrm{A} t_{s}^{n}$, where $\mathrm{A}$ and $n$ are constants. ${ }^{[9]}$ It was found that $n$ is between 0.28 and 0.5 for most metallic alloys. ${ }^{[4,9-13]}$ This correlation enables analysis of the dependence of SDAS with the cooling rate, which is inversely proportional to $t_{s}$. Coarsening in secondary dendrite arms has been well documented in the literature, where $n$ is considered to be constant. ${ }^{[1-4,7-13]}$ However, much of the analysis in coarsening made in the past, for metallic-opaque systems, was done over postsolidified samples. By this means, it is not possible to observe local velocity fluctuations and real-time evolution of microstructure. Many of the experimental studies reported in the past were also carried over steady-state solidification conditions. ${ }^{[9]}$ In real cast processes, solidification will most often involve transient growth velocities due to thermal gradients existing according to the cast dimensions and shape. Transient solidification conditions have proven to influence microstructure. In addition, the solidification direction (with respect to gravity) influences liquid 
flow and thus the development of dendrites. ${ }^{[14,15]}$ It has been found that the primary dendrite arm spacing becomes larger when solidifying upward due to solute accumulation between dendrites. ${ }^{16-18]}$ Drainage or enrichment of rejected solute during growth depends on the direction of growth. ${ }^{[17]}$ Also, this depends on the density of rejected solute ${ }^{[18]}$ e.g., drainage occurs during downward solidification for the case of alloys with high density solute elements. ${ }^{[17]}$ Liquid flow due to transient conditions and the direction of solidification may not only affect the primary spacing but also the development of high-order branches deep in the mush. ${ }^{[17]}$

The present study was based on downward continuous directional solidification experiments. In-situ analysis of coarsening during simultaneous development of coarsening and growth of a dendrite is presented. Moreover, inherent transient solidification conditions occurring during growth permit us to study the effect of such conditions on coarsening.

\section{EXPERIMENTAL PROCEDURE}

Downward (i.e., parallel to gravity) directional solidification experiments were done by using a Bridgmanlike furnace system. The solidification of an Al-30 wt pct $\mathrm{Cu}$ alloy was studied. Samples were rectangular slices with dimensions of $1.5 \times 3.0 \mathrm{~cm}^{2}$ and $200-\mu \mathrm{m}$ thickness. The slices were preoxidized at $720 \mathrm{~K}$ for 2 hours, and then spray coated with boron-nitride. The sample was placed in the furnace system after being encapsulated between $100-\mu \mathrm{m}$-thick quartz glass plates.

Experiments were done at the European Synchrotron Radiation Facility (ESRF) at beam line ID22 under code HS-1332. A flux density at the sample of $5 \cdot 10^{12}$ photons $/\left(\mathrm{mm}^{2} \cdot \mathrm{s}\right)$ was achieved by using monochromatic X-ray energy of $15 \mathrm{KeV}$. Detector dead time of 0.15 seconds and exposure time of 0.3 seconds permitted image acquisition every 0.45 seconds (i.e., grabbing rate of $2.22 \mathrm{~s}^{-1}$ ). In total, a sequence of 120 images was taken. The field of view of such images was $1.35 \times$ $1.35 \mathrm{~mm}^{2}$.

Solidification was facilitated by slowly translating the molten sample upward (opposite to gravity) at a constant pulling velocity $v_{s p}=-22.5 \mu \mathrm{m} / \mathrm{s}$, from the hot section into the cold section of the furnace system. Downward solidification (solid-liquid interface displacement parallel to gravity) was achieved by these conditions. A thermal gradient $G_{T}=27 \mathrm{~K} / \mathrm{mm}$ was imposed during solidification. Images were recorded as soon as the solidification front appeared in the field of view (at $t_{\exp }=-9.0 \mathrm{~s}$ ). A detailed explanation of the current experiment can be found in Reference 19. For other relevant information concerning the experimental setup and X-ray microscopy, refer to Reference 20.

Coarsening of the secondary dendrite arms developing during continuous solidification was characterized by measuring the SDAS parallel to the main dendrite trunk at different local solidification times determined according to the depth in the mush. This was done considering four regions within the mushy zone. The average SDAS was then measure over the secondary dendrite arms

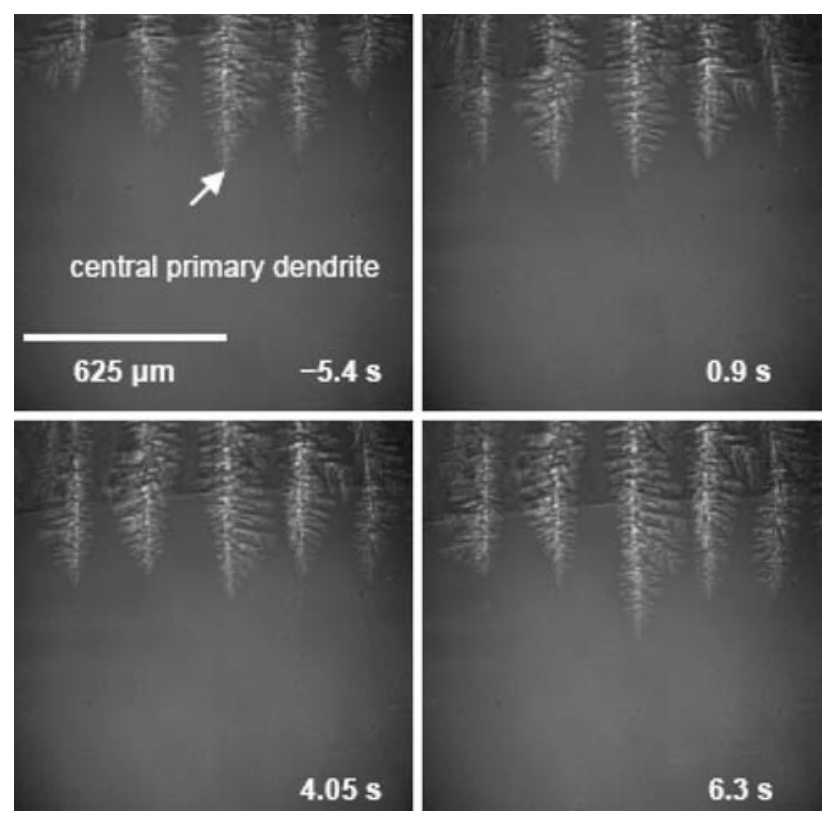

Fig. 1-Fields of view taken at $t_{\exp }=-5.4,0.9,4.05$, and $6.3 \mathrm{~s}$.

contained between the limits of the selected region at each image. Error estimation of such measurements was obtained statistically according to the deviation of the measurements within the region.

The local solidification time $t_{s}$ was determined from ${ }^{[2]}$

$$
t_{s}=\frac{a}{v_{s l}}
$$

where $a$ corresponds to the depth within the mush and $v_{s l}$ the velocity of the primary dendrite tip. The average local solidification time was estimated for each of the four regions delimited within the mush, taking into consideration the instant velocity of the selected dendrite (central primary dendrite in Figure 1). Error measurements of the average $t_{s}$ were estimated based on its deviation according to the local solidification times at the boundaries of the region according to $a$ where the SDAS were measured.

\section{RESULTS}

Figure 1 shows some of the images taken at different times $t_{\text {exp. }}$. For the present investigation, the central primary dendrite from the field of view in Figure 1 was studied. Regions of interest (ROIs) were made around this dendrite in order to perform the SDAS measurements. Figure 2 demonstrates four of the ROIs taken at $t_{\exp }=-5.4,0.9,4.05$, and 6.3 seconds from those shown in Figure 1.

Velocity fluctuations were observed during the experiment. The corresponding solidification front velocities were determined previously for the three primary dendrites trunks observed in the center of the field of view (Figure 1). ${ }^{[19]}$ In the present analysis, the velocity changes of the central primary dendrite (Figure 1) were employed for the estimation of $t_{s}$. The sequence of 


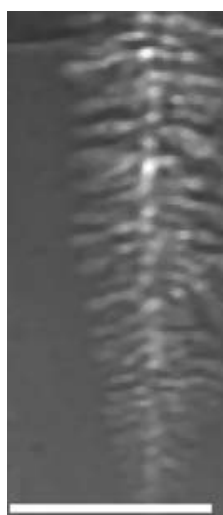

$186 \mu \mathrm{m}$
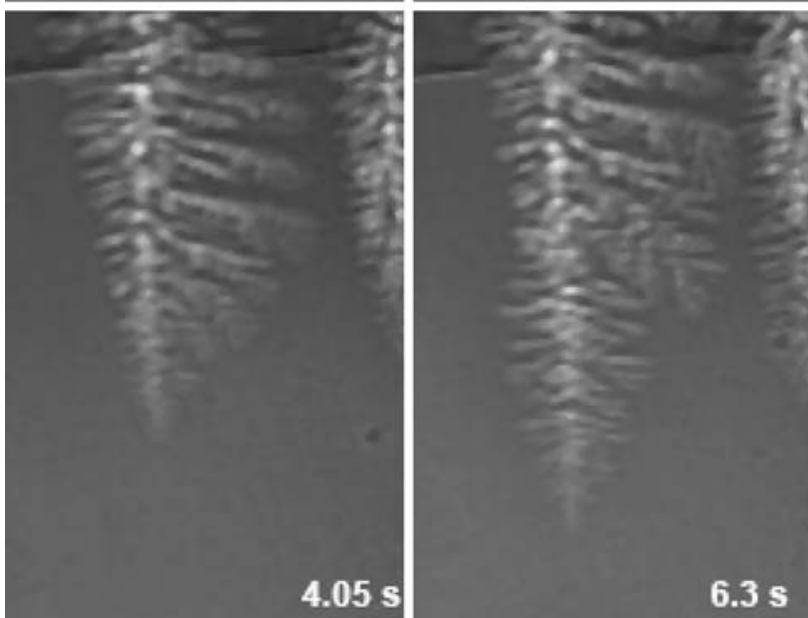

Fig. 2-ROIs taken around the central primary dendrite at $t_{\exp }=$ $-5.4,0.9,4.05$, and $6.3 \mathrm{~s}$.

images considered corresponds to deceleration $\sim-4.9 \mu \mathrm{m} / \mathrm{s}^{2}$ and acceleration of the solidification front $\sim 13.7 \mu \mathrm{m} / \mathrm{s}^{2}$. These transient conditions occur naturally during solidification. Mathiesen and Arnberg ${ }^{[19]}$ explained these fluctuations to occur during growth due to the continuous solute pileup at the solidification front and settlement at a certain accumulation. High-density solute-rich liquid settles down due to gravity and a cleaner melt enables development of a new boundary layer.

Figure 3 demonstrates the SDAS as a function of the local solidification time $t_{s}$. Coarsening and growth occurred simultaneously during solidification. There was a difference in coarsening kinetics at the left and right sides of the primary dendrite trunk. Therefore, SDAS measurements were done at the left and right sides of the primary dendrite during deceleration and acceleration. Figure 3(a) shows similar kinetics of gradual spacing development at both sides during deceleration. In this case, the SDAS close to the eutectic front is $\sim 43 \mu \mathrm{m}\left(t_{s}=11\right.$ seconds). It was observed that during deceleration, the coarsening mechanism is dissolution from tip to root of some secondary dendrite arms and thickening of others. This coarsening mechanism occurred moderately. On the other hand, the right side of the dendrite presented more pronounced coarsening

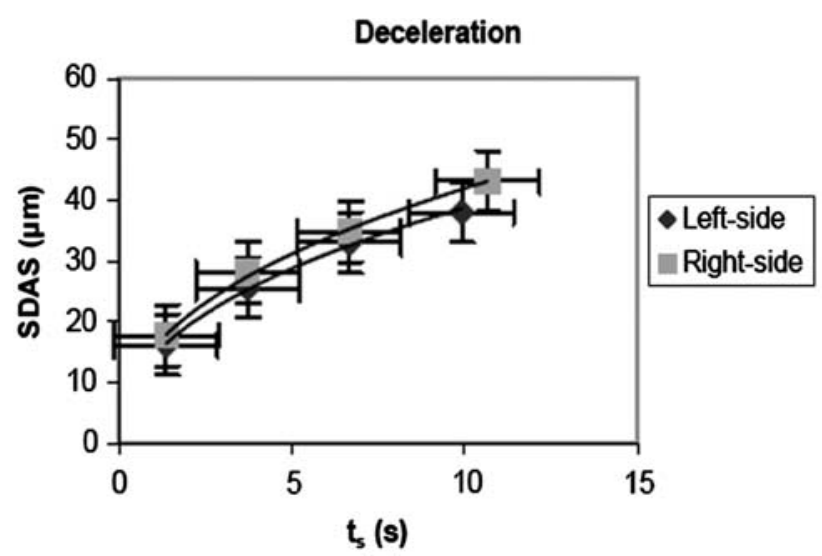

(a)

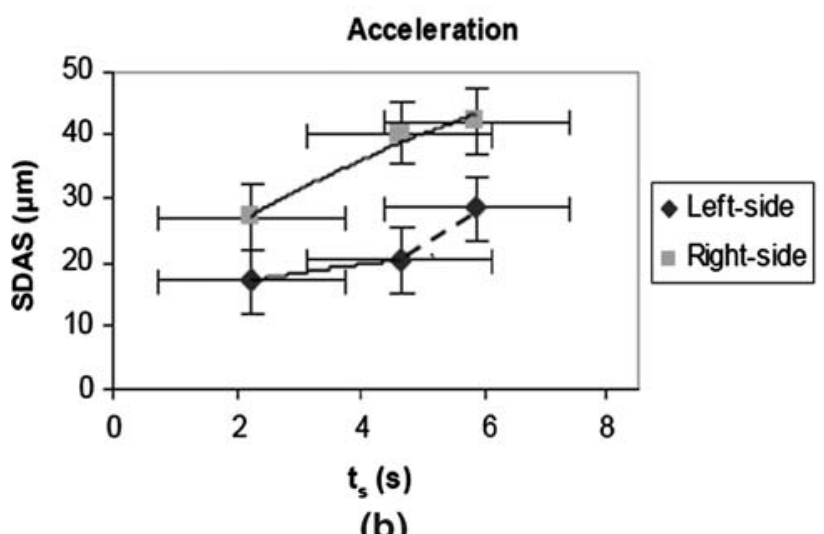

Fig. 3-SDAS as a function of solidification time $t_{s}$ during $(a)$ deceleration and $(b)$ acceleration of the solidification front.

by dissolution, having some dendrite arms left behind while others continue growing. Also, a moderate growth of tertiary dendrite arms was observed. Moreover, at both sides, no complete dissolution within the mushy zone was observed in those arms that were left behind.

On the other hand, during acceleration (Figure 3(b)), the kinetics of the SDAS development differ strongly from one side to another, and from the kinetics found during deceleration. During acceleration, at the left side, at $t_{s}$ between 2 and 5 seconds, the slope is moderate, and then a sudden steeper change is shown after 5 seconds (dotted line in Figure 3(b)). This abrupt change is due to the coarsening mechanism, which is dissolution from the tip toward the root of neighboring secondary dendritic arms, being quite severe near the eutectic front. Dendrite arms that tend to dissolve are left behind and are no longer considered during the SDAS measurements, and then only surviving neighboring dendrite arms are taken into account. In contrast, the right side shows a more prominent growth of tertiary dendrite arms, and dissolving secondary arms become enclosed by these developing branches (Figure 4). In addition, the SDAS is larger than the SDAS at the left side and the SDAS during deceleration. Furthermore, during acceleration, both sides have prominent coalescence between secondary dendrite arms that collapse as the dendrite continues developing. 


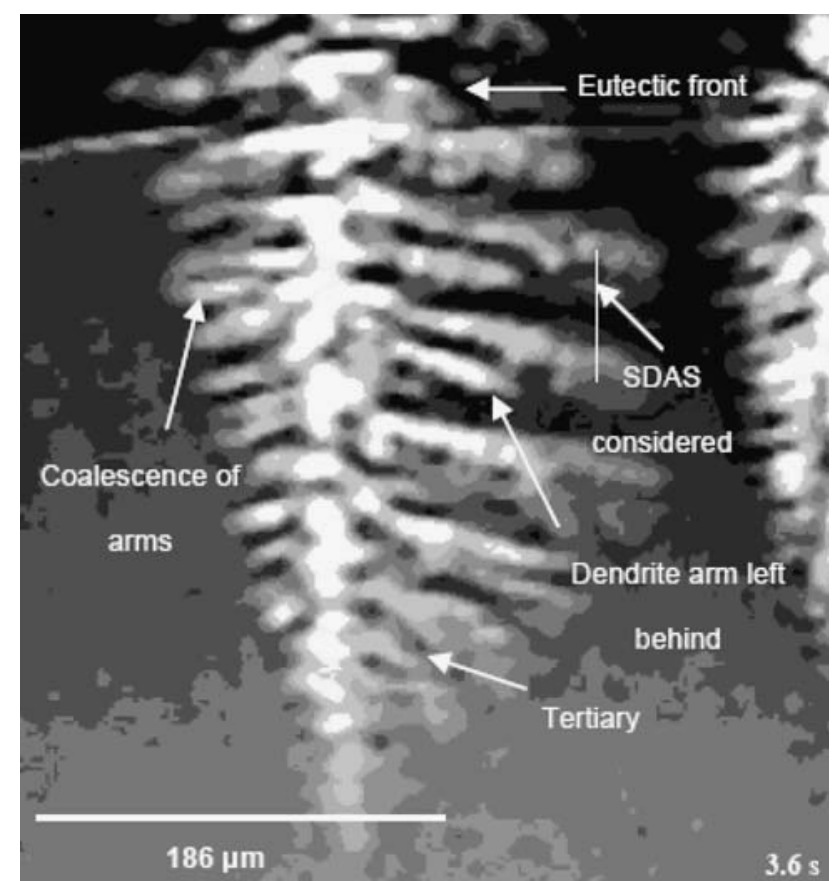

Fig. 4-Magnification over image taken at $t_{\exp }=3.6 \mathrm{~s}$, which develops during acceleration, demonstrating the distinct coarsening mechanism operating during solidification.

From the corresponding curves in Figure 3, a correlation between the SDAS and $t_{s}$ was estimated. Linear regression analysis was used to determine the relationship SDAS $\sim t_{s}^{n}$. During deceleration, the SDAS $\sim t_{s}^{0.4}$ at both sides of the dendrite trunk. On the other hand, during acceleration, the SDAS $\sim t_{s}^{0.28}$ at the left side of the primary dendrite at $t_{s}$ between 2 and 5 seconds, and then changes abruptly to SDAS $\sim t_{s}^{0.4}$, whereas the $\mathrm{SDAS} \sim t_{s}^{0.5}$ at the right side during acceleration.

\section{DISCUSSION}

The average total mush depth, from the tip of the dendrite to the eutectic front, adjusts in length with the velocity of the solidification front. During deceleration, the mush depth diminishes gradually from a starting measured depth of $\sim 440 \mu \mathrm{m}$ ( $t_{\exp }=-5.4$ seconds $)$. At the end of the deceleration stage $\left(t_{\exp }=0.9\right.$ seconds), the mush depth is $\sim 335 \mu \mathrm{m}$; then it increases gradually when acceleration starts. During acceleration, the mush length adjusts at the end to $\sim 390 \mu \mathrm{m}\left(t_{\exp }=6.3 \mathrm{sec}-\right.$ onds). The equilibrium mush depth, according to the equilibrium freezing range $\Delta T_{0}$ and $G_{T}$, can be calculated from $a_{e q}=\Delta T_{0} / G_{T}$, where $\Delta T_{0}=m\left(C_{0}-C_{e}\right)$, $m=-4.9 \mathrm{~K} /$ wt pet $\mathrm{Cu}$ is the equilibrium liquidus slope obtained from the Al- $\mathrm{Cu}$ diagram, $C_{0}$ is the nominal composition (30 wt pct $\mathrm{Cu}$ ), and $C_{e}$ is the eutectic composition $(33.1 \mathrm{wt}$ pct $\mathrm{Cu}) .{ }^{[2]}$ The calculated equilibrium depth is $a_{e q}=560 \mu \mathrm{m}$, compared to the maximum depth observed before deceleration starts $(\sim 440 \mu \mathrm{m}), \Delta a=\left(a_{e q}-a\right)=120 \mu \mathrm{m}$; the difference is quite large. This highlights the effect of downward solidification and transient solidification conditions over the microstructure. It should be noted, however, that this analysis was done considering roughly the length of the primary dendrite, and the purpose of such analysis is only to relate its particular development to transient conditions and comparison with $a_{e q}$. The transient development of neighboring primary dendrites would affect the local mush depth at the left and right sides of the central primary dendrite. An average local depth analysis at both sides of the central dendrite would demonstrate the effect of primary spacing and velocity growth fluctuations with the microstructure (not presented here).

The solidification time is affected by these fluctuations in a similar manner, where the local solidification time becomes shorter during acceleration than during deceleration (Figure 3). Accordingly, it should be expected that more coarsening will occur at longer solidification times. This is evident in Figure 3(a), where the SDAS is larger at both sides of the dendrite compared to the left side of the same dendrite during acceleration. On the other hand, the right side, during acceleration, has a larger SDAS to that found during deceleration. During acceleration, it is evident that both sides of the dendrite behave differently. From the observations of the sequence of images (Figure 1), the spacing with neighboring primary trunks is different. The neighboring dendrite at the left side is a little farther away compared to the neighboring dendrite at the right side. The distance between dendrite trunks influences liquid flow. During downward growth, solute rejection and flow of the solute-rich liquid deep in the mush toward the solidification front (settlement) is easier at the left side (more permeable) than at the right side (less permeable) due to spacing between neighboring dendrites. This may explain the different solidification behavior at both sides of the central primary dendrite trunk. Deceleration occurs due to solute pileup at the front. The undercooling required for growth at the solidification front is diminished due to dissipation of solute gradients. Solute-rich liquid accumulates at both sides. A highsolute environment promotes coarsening by material transport due to curvature differences at both sides. After certain saturation, solute-rich liquid settles due to gravity and vacates the mushy region with an unsaturated melt, as described by Mathiesen and Arnberg. ${ }^{[19]}$ During this evacuation, a solute gradient again builds up, causing acceleration of growth at the front. At the left side (permeable region), evacuation of the soluterich liquid from the mushy zone dissipates solutal gradients and thus undercooling. Solute-rich liquid displacement toward the solidification front drags the undercooling at the front; this is why the front tends to accelerate its growth. On the other hand, the mushy zone between the central primary dendrite and right side primary dendrite is less permeable. Thus, during growth and solute rejection, solute-rich liquid becomes trapped by the developing dendrite branches. Solute enrichment occurs, promoting a solutal gradient, which enables growth. This is why growth of tertiary dendrite arms is largely observed at the right side. Moreover, coarsening at this region may be enhanced due to solute enrichment. However, growth may be the dominating factor for the increase in the SDAS. Whereas high permeability 
at the left side enables replacement of a clean melt, which diminishes coarsening and growth, this is another cause (apart from a lowering in $t_{s}$ ) for the SDAS to be lower during acceleration. The sudden increase in slope at this region in the SDAS (Figure 3(b), left side) may be due to the solute that accumulated between the large secondary dendrite arms near the eutectic and did not flow. This enrichment near the eutectic causes coarsening of dendrite arms.

\section{CONCLUSIONS}

In-situ analysis of coarsening was done on an Al-30 wt pct $\mathrm{Cu}$ alloy during continuous directional solidification experiments. Fluctuations in the solidification front velocity occurred naturally due to accumulation and settlement of solute-rich liquid. These fluctuations permitted the analysis of coarsening during deceleration and acceleration of the solidification front. The SDAS measurements were used to characterize coarsening during solidification. It was found that during deceleration, the SDAS increases gradually as $\mathrm{SDAS} \sim t_{s}^{0.4}$. In the current observations, the proximity of neighboring dendrites (or primary dendrite arm spacing) has no effect on the SDAS during deceleration. In contrast, during acceleration, the dendritic arrangement affects coarsening. In this case, it was found that secondary dendrite arms coarsen more and develop tertiary dendrite arms when they are close to a neighboring dendrite (less permeable region). This is probably due to solute accumulation, which causes coarsening, and the build up of solute gradients that promote the necessary undercooling for growth. Under these conditions, it was found that the SDAS $\sim t_{s}^{0.5}$. On the other hand, a more permeable region enables drainage of solute-rich liquid, diminishing solute accumulation and coarsening. Also, dissipation of solute gradients at this region diminishes undercooling, thus lowering growth. The liquid flow and dendritic arrangement affect the solidification process by altering the local undercooling within the mush and therefore the local growth dynamics.

\section{ACKNOWLEDGMENTS}

This work was carried out under Project No. MC4.02134b in the framework of the Research Program of the Materials Innovation Institute $\mathrm{M} 2 \mathrm{i}$ (www.m2i.nl), the former Netherlands Institute for Metals Research, along with the Nor-Light Shaped Casting project, with the following partners: Alcoa
Automotive Castings; Scandinavian Castings Center ANS; Elkem Aluminium ANS; Fundo Wheels AS; Hydro Aluminium Metal Products; Hydro SA, Hydro Magnesium; NTNU; NIMR; and SINTEF. The authors acknowledge the industrial partners and the Norwegian Research Council, for their financial support, and the European Synchrotron Radiation Facility, for granting beam time to the experiment under code HS-1332. We thank Dr. Q. Du for his advice in performing the correct SDAS measurements during continuous directional solidification.

\section{OPEN ACCESS}

This article is distributed under the terms of the Creative Commons Attribution Noncommercial License which permits any noncommercial use, distribution, and reproduction in any medium, provided the original author(s) and source are credited.

\section{REFERENCES}

1. M.C. Flemings: Solidification Processing, McGraw-Hill, New York, NY, 1974.

2. W. Kurz and D.J. Fisher: Fundamentals of Solidification, 3rd ed., Trans Tech Publications, Aedermannsdorf, Switzerland, 1992.

3. Q. Du, D.G. Eskin, A. Jacob, and L. Katgerman: Acta Mater., 2007, vol. 55, pp. 1523-32.

4. T.Z. Kattamis, J.C. Coughlin, and M.C. Flemings: Trans. TMSAIME, 1967, vol. 239, pp. 1504-11.

5. A.A. Chernov: Kristallografiya, 1956, vol. 1, pp. 583-87.

6. M.O. Klia: Kristallografiya, 1956, vol. 65, pp. 576-81.

7. M. Kahlweit: Scripta Metall., 1968, vol. 2, pp. 251-54.

8. S.C. Huang and M.E. Gliksman: Acta Metall., 1981, vol. 29, pp. 717-34.

9. T.Z. Kattamis and M.C. Flemings: Trans. TMS-AIME, 1965, vol. 233, pp. 992-99.

10. T.F. Bower, H.D. Brody, and M.C. Flemings: Trans. TMS-AIME, 1966, vol. 236, pp. 624-34.

11. K.P. Young and D.H. Kirkwood: Metall. Trans. A, 1975, vol. 6A, pp. 197-205.

12. Y.L. Liu and S.B. Kang: Mater. Sci. Technol., 1997, vol. 13, pp. 331-36.

13. V. Rontó and A. Roósz: Int. J. Cast Met. Res., 2001, vol. 13, pp. $337-42$.

14. J.E. Spinelli, M.D. Peres, and A. Garcia: J. Alloys Compd., 2005, vol. 403, pp. 228-38.

15. R.N. Grugel: J. Mater. Sci., 1993, vol. 28, pp. 677-83.

16. N. Tunca and R.W. Smith: J. Mater. Sci., 1998, vol. 23, pp. 111-20.

17. R.H. Mathiesen, L. Arnberg, P. Bleuet, and A. Somogyi: Metall. Mater. Trans. A, 2006, vol. 37A, pp. 2515-24.

18. M.H. Burden and J.D. Hunt: Met. Sci., 1976, pp. 156-58.

19. R.H. Mathiesen and L. Arnberg: Adv. X-Ray Anal., 2006, vol. 49, pp. $37-45$.

20. R.H. Mathiesen, L. Arnberg, K. Ramsøskar, T. Weitkamp, C. Rau, and A. Snigirev: Metall. Mater. Trans. B, 2002, vol. 33B, pp. 613-23. 